\title{
Factors influencing the quality of life perceptions of cognitively impaired older adults in a nursing home and their informal and professional caregivers: a mixed methods study
}

This article was published in the following Dove Press journal:

Clinical Interventions in Aging

\author{
Henk Verloo' \\ Alexandre Salina ${ }^{2}$ \\ Assunta Fiorentino ${ }^{3}$ \\ Christine Cohen ${ }^{3}$ \\ 'School of Health, Department of \\ Nursing Valais - Wallis, HES-SO \\ University of Applied Sciences and \\ Arts Western Switzerland, Sion, \\ Switzerland; ${ }^{2}$ Home Salem Nursing \\ Home, Eben-Hézer Foundation, Saint- \\ Légier, Switzerland; ${ }^{3}$ La Source, School \\ of Nursing, HES-SO University of \\ Applied Sciences and Arts Western \\ Switzerland, Lausanne, Switzerland
}

Background: Identifying the objective and subjective aspects of the quality of life (QoL) of institutionalized cognitively impaired older adults (CIOAs) is a challenge. However, it can reveal which aspects of their care require improvement.

Aim: The aim of this study was to identify the core aspects of the QoL of CIOAs living in a nursing home (NH) by involving informal and professional caregivers (PCs).

Methods: Our sequential, mixed methods study exploring the QoL of CIOAs was based on Lodgson et al's (2002) quantitative quality of life-Alzheimer's disease (QoL-AD) questionnaire. Subsequently, a qualitative phase study analyzed perceptions and impressions of QoL using interviews of CIOAs and their most significant informal caregivers (SICs) and PCs.

Results: Fifteen CIOAs, 12 SICs, and 2 PCs were recruited. Two-thirds of the older adults were females, overall average age was 86 years $(\mathrm{SD}=6.1)$, and all had a severe clinical dementia rating $(\mathrm{CDR}=3)$. A high level of comorbidity (measured using the Cumulative Illness Rating Scale for Geriatrics) was significantly associated with a lower QoL-AD score $(P=0.046)$. Higher numbers of visits by SICs or family members had a positive effect on QoL-AD scores $(P=0.036)$. No significant differences were found in overall QoL-AD scores as rated by CIOAs, SICs, and PCs $(P=0.080)$. Combining quantitative and qualitative data analyses revealed four significant themes influencing the QoL of CIOAs: 1) human dignity and acceptance; 2) development and existence; 3) functionality and health; and 4) recognizability and safety.

Conclusion: Sequentially using mixed methods proved an appropriate way to examine the QoL of severe CIOAs living in an $\mathrm{NH}$, and these results were compared with the perceptions of informal and PCs. The factors optimizing overall health were visits by SICs and family members, and the major aspect that increases the QoL was freedom of movement inside and outside the NH.

Keywords: content analysis, nursing homes, old age psychiatry, older adults, dementia, behavioral and psychological symptoms of dementia, objective QoL, subjective QoL, functional QoL

\section{Introduction}

There are $\sim 65,000$ institutionalized older adults (OAs) presenting with severe neurocognitive disorders in Switzerland, and that number is constantly increasing. ${ }^{1,2}$ Dealing with the needs of these cognitively impaired older adults (CIOAs) is very often complex, and ensuring optimal care is a daily challenge for their carers. ${ }^{3,4}$ In response to these complex needs, nursing homes (NHs) must rethink the care they provide to 
contribute to the quality of life (QoL) of OAs. ${ }^{5}$ In addition to the communication difficulties with CIOAs, the literature documents the disruptive behaviors that complicate the evaluation of QoL. ${ }^{6,7}$ Previous authors have described two concepts central to determining the QoL among CIOAs in NHs: a suitably adapted environment or accommodation and specific interventions related to the disruptive behavior. ${ }^{3,8,9}$ Swiss guidelines (2015) suggest that CIOAs living with different physical and cognitive disabilities should be offered architectural and organizational adaptations to their lives. This could increase the flexibility, both in relation to the pace of their lives and different possible living arrangements, but it would also consider the QoL as a clinical outcome of the optimized quality of care. ${ }^{10,11}$ For carers, these good practice guidelines recommend developing and introducing multifaceted approaches made up of psychosocial nondrug interventions. These approaches could be music, validation techniques, reminiscence therapy, Snoezelen rooms, Montessori methods, time slips, or even evaluations of and strategies for managing the behavioral and psychological symptoms of dementia (BPSD). These nondrug approaches can be complemented with evidence-based drug treatments. ${ }^{9}{ }^{12-14}$ The aim of all these changes is to contribute to a better QoL, now and for the rest of CIOAs' lives, and the optimal fulfillment of their wishes. If we start with the assumption that all human beings wish to reach or maintain an optimal QoL, then how can we identify the factors that characterize the QoL of OAs living in NHs when they have problems in communicating?

Different methods of evaluating QoL have been documented, and they are mainly determined by physiological abilities. ${ }^{15,16}$ Although there is no universal consensus on a definition for QoL, the present study adopts that of the WHO (1993), which proposes that QoL is linked to individuals' perceptions of their position in life in the context of the culture and value systems in which they live and in relation to their goals, expectations, standards, and concerns. ${ }^{17,18}$ As such, the concept of QoL is based on a broader understanding of quality, including objective, subjective, and functional determinants. In the present study, objective determinants of QoL are represented by measurable physical and cognitive disabilities. The subjective determinants examined are political and philosophical beliefs - an assessment of one's life according to one's values and the objectives that form one's personal conceptions of a successful life. Finally, the present study's functional determinants were qualities, skills, and resources, which enabled OAs to optimally adapt to different situations and maintain their QoLs. ${ }^{19,20}$

\section{Study framework}

We adopted the hierarchical framework for QoL in dementia described by Jonker et al. ${ }^{1,21}$ This framework incorporates all the components of the life of CIOA, including those not affected by dementia, and it relates the factors of dementia and the environment as well as personal factors to know how they influence overall well-being. The framework establishes causal pathways linking different types of outcomes to each other, and it was empirically tested by Rabins and Black. ${ }^{22}$ Environmental and personal factors also influence the domains affected by dementia. Psychological well-being is assigned to the framework's highest level, described as the subjective evaluation of life in general. This means that the subjective evaluation of the various relevant (life) domains determines psychological well-being in general. These various domains have their own contributions to each individual's psychological well-being. For instance, the loss of autonomy in the activities of daily living (ADLs), such as dressing and washing oneself, may be important for one individual's QoL, but less so or even not important for another's. According to the framework described by Jonker et al, QoL can be measured at three levels and is coherent with our study aim, although the importance of the domains in the QoL framework may vary across individuals. This framework could be useful for formulating strategies to improve QoL among OAs suffering from dementia.

Consistent with the WHO's definition, QoL must be considered as the ultimate objective of long-term care structures. ${ }^{23,24}$ As a result, a combined objective, subjective, and functional study of the QoL of CIOAs living in NHs must consider multiple variables and evaluation strategies.

The purpose of the present study was to examine the QoL among CIOAs living in NHs by involving the OAs themselves, along with their significant informal and professional caregivers (PCs). One specific aim was to explore CIOAs' perceptions of the functional aspects of their QoLs. To meet these aims, a mixed methods research design was imperative to understand the objective and subjective components of QoL among CIOAs and to combine these findings with the intent to obtain a more comprehensive understanding of their QoLs in the NH.

\section{Materials and methods Study design}

This sequential, mixed methods study examined objective components of the QoL of CIOAs living in an NH, using tools measuring autonomy, health status, comfort, and social aspects of daily living (quantitative study). In a 
second phase, a qualitative study explored the perceptions and significance of QoL through individual interviews with the CIOAs recruited in NHs and their significant informal caregivers (SICs). The rationale for adding the qualitative component was the opportunity to gain a detailed understanding of "the experiences and feelings of the everyday QoL of CIOAs suffering from severe dementia in an $\mathrm{NH}$ as well as the perceptions of that QoL as expressed by their SICs." Figure 1 shows the sequential mixed methods study design.

\section{Population, sampling, and procedures}

The study population was composed of CIOAs living in the psychiatric unit of one $\mathrm{NH}$ in French-speaking Switzerland, their SICs, and their PCs (nurses and occupational therapists). The study nurse recruited participants in collaboration with the psychiatric unit's nursing supervisor. Recruitment took place between January and September 2016.

\section{Quantitative study}

\section{Study population}

All CIOAs (and their legal representatives), men and women who had been living in the unit for at least 2 weeks, were invited to participate in the study. CIOAs in end-of-life situations were excluded. Eligible SICs, regularly involved in caring for a CIOA, and psychiatric unit nurses and occupational therapists (OTs), who had been employed there for at least 1 month, were also invited to participate in the study.

\section{Primary outcome \\ Quality of life-Alzheimer's disease - French version (QoL-AD-fv)}

QoL-AD questionnaire was developed by Logsdon et $\mathrm{a}^{25}$ in 1999 for CIOAs presented with moderate to severe cognitive impairments (Mini-Mental State Examination [MMSE] score $\leq 12$ ). The QoL-AD has been translated, culturally adapted, and psychometrically validated in French (QoL-AD-fv). ${ }^{26}$ The tool includes 13 items assessing the domains of physical health; mood; life circumstances; memory; relationships with spouse, family, and friends; hobbies; the activities of daily life; financial aspects; self-esteem; and satisfaction with life, which was scored on a 4-point Likert scale (1=poor QoL to $4=$ excellent QoL). Total score can vary between 13 (poor QoL) and 52 points (excellent QoL). The cutoff points among poor, moderate, good, and excellent QoLs were not explored in either the original or the French questionnaire. The QoL-AD-fv showed excellent internal coherence with Logsdon et al' $\mathrm{s}^{27}$ original version and Wolak et al' $\mathrm{s}^{26}$ translated, validated version, showing Cronbach's alphas of 0.88 and 0.83 , respectively. QoL-AD-fv was chosen for its specificity; its range of dimensions of QoLs; its rapid, 15-minute administration time; its ease of use in different living spaces; the fact that it can be administered by a SIC or a PC, and, finally, its proven psychometric qualities. ${ }^{26,28-30}$ Although problems of cognitive impairment are often cited as limitations to a person's ability to express their opinions on their QoL, ${ }^{22}$ Moyle et a ${ }^{31}$ demonstrated that CIOAs were able to discuss important aspects of their QoLs with the aid of an interview. Interviews began with an open-ended question

\begin{tabular}{|c|c|c|}
\hline \begin{tabular}{l}
\multicolumn{1}{l}{ Quantitative design } \\
Sample: \\
Fifteen CIOAs, nine SICs, and \\
two PCs. \\
Data collection: \\
Measuring QoL-AD-fv, autonomy, \\
health status, comfort, \\
and social aspects of daily living. \\
Primary outcome: \\
Scores QoL-AD-fv. \\
Secondary outcome: \\
Functional, cognitive, and \\
depression status, comorbidities, \\
pain and number of medications.
\end{tabular} & $\begin{array}{l}\text { Qualitative interview study } \\
\text { Sample: } \\
\text { Fifteen CIOAs and nine SICs. } \\
\text { Methods: } \\
\text { Individual interviews of CIOAs } \\
\text { and SICs. } \\
\text { Outcome: } \\
\text { Perceptions of quality of life. }\end{array}$ & $\begin{array}{l}\text { Mixed methods analysis } \\
\text { Methods: } \\
\text { Integration of questionnaire results } \\
\text { and interview results. } \\
\text { Outcomes: } \\
\text { - Overaching results: perceptions } \\
\text { of quality of life. } \\
\text { - Comprehensive understanding } \\
\text { of objective, subjective and, } \\
\text { functional components } \\
\text { influencing quality of life. }\end{array}$ \\
\hline
\end{tabular}

Figure I Sequential mixed methods study design.

Abbreviations: CIOA, cognitively impaired older adult; PC, professional caregiver; QoL-AD-fv, quality of life-Alzheimer's disease - French version; SIC, significant informal caregiver. 
aimed at probing the OA's perception of QoL: "What do you think influences your quality of life?" Follow-up questions, depending on the CIOA's capacities, further explored the physical, psychological, social, and relational dimensions of QoL, as well as its meaning to their life. ${ }^{32}$

\section{Secondary outcomes}

\section{Functional assessment}

Previous studies have reported that the functional status of OAs is most appropriately assessed using scores for autonomy in the ADLs. ${ }^{33,34}$ The present study assessed the functional status using the Katz index of ADL. ${ }^{35}$ The Katz index of ADL scale is a well-established and documented too $^{36}$ used to assess independence vs dependence in the areas of bathing, dressing, mobility, grooming, incontinence, and feeding. ADLs were assessed by the study nurse and sometimes by the primary investigator (PI), with an excellent interrater Cohen's kappa of 0.85 .

\section{Cognitive assessment}

All participants had been previously diagnosed with dementia. Cognitive level was assessed using the $\mathrm{MMSE}^{37}$ by combining the seven domains of cognitive functioning. This 11-item instrument measures orientation, memory, and language and psychomotor skills. The sum of the scores varies from 0 (severe cognitive impairment) to 30 (no cognitive impairment). A score of fewer than 24 points was considered as the cutoff point for cognitive impairment. MMSEs were mostly carried out by the study nurse and the PI, and the instrument presented good psychometric properties. ${ }^{38,39}$ The interrater ratio calculated between the study nurse and the PI showed an excellent intraclass correlation of 0.92 .

\section{Clinical dementia rating (CDR)}

The CDR scale was used for staging dementia, taking only a few minutes to classify OAs with dementia into the questionable, mild, moderate, and severe stages. ${ }^{40}$ The CDR characterizes six domains of cognitive and functional performance applicable to Alzheimer's disease and related dementias, each assessed on a 5-point scale: memory, orientation, judgment and problem solving, community affairs, home and hobbies, and personal care. Ratings were obtained by interviewing an SIC and the unit's nurse. The CDR characterized each CIOA's level of impairment/dementia as follows: $0=$ normal; $0.5=$ very mild dementia; $1=$ mild dementia; $2=$ moderate dementia; and $3=$ severe dementia. In previous studies, the CDR showed sensitivity of 0.74 and specificity of $0.81 .^{41}$

\section{Assessment of delirium}

Delirium was assessed using the validated French version of the Confusion Assessment Method (CAM). ${ }^{42}$ The CAM is an instrument developed to assist clinicians in identifying patients with delirium. It has been considered suitable for the bedside use. ${ }^{43}$ The psychometric properties of the CAM have been documented as excellent, with 94\% sensitivity, $89 \%$ specificity, and an interrater reliability kappa of between 0.70 and $1.00 .{ }^{43}$ Either the study nurse or the PI completed the CAM form based on an interview, patient records, and clinical observation of the symptoms and signs described in the CAM. Data were subsequently analyzed categorically using the CAM algorithm. Interrater reliability between the PI and the study nurse (trained in CAM assessment) showed a satisfactory Cohen's kappa coefficient of $0.79 .{ }^{44}$

\section{Cumulative illness rating scale for geriatrics (CIRS-G)} The study nurse assessed comorbidity rates using the CIRS-G. ${ }^{45}$ Miller et $\mathrm{l}^{46}$ (1992) adapted this tool for hospitalized OAs. ${ }^{46}$ The CIRS-G assesses 15 physiological systems all scored on a 5-level scale of severity from $0=$ absence of an organic impairment or system to $4=$ severe and very severe impairment due to illnesses and risk of early death. The total score can vary from 0 to 60 . A score from 0 to 15 means a low level of illness severity, with low impact on patient capacities; $16-30$ indicates a moderate impact on patient capacities; $31-45$ suggests the presence of severe illnesses and permanent incapacities; and a score from 46 to 60 indicates the presence of very severe illnesses requiring immediate treatment and a risk of hospitalization. The literature documents an intraclass correlation fidelity score of 0.83 and an interrater score of 0.81 (Pearson's $r$ ). ${ }^{3}$ Applying Huntley et al's (2012) best practice recommendations, information on patients' pathologies was taken from their NH medical records and confirmed during interviews with the CIOAs and their SICs. ${ }^{46,47}$

\section{The Cornell Scale for Depression in Dementia}

The Cornell Scale for Depression in Dementia is a 19-item clinician-administered screening tool using information from interviews with the patient and a member of the nursing staff, a method suitable for patients with dementia. The scale has high interrater reliability $(k=0.67)$ and internal consistency (coefficient alpha=0.84), and the elevated sensitivity of the total Cornell Scale score correlates (0.83) with depressive subtypes of various intensity classified according to Research Diagnostic Criteria. ${ }^{48}$ 


\section{Algoplus ${ }^{\circledR}$ Scale}

Pain was evaluated using the Algoplus Scale, which measures acute pain in OAs unable to communicate verbally. Each of the scale's five items scores 0 (absence of pain) or 1 (presence of pain), total scores vary from 0 to 5 , and thus, higher scores indicate greater pain.

\section{Medication}

Numbers of prescribed medicines were assessed using OAs' charts and verified during the PI's first visit to the NH. No further analysis was done.

\section{Sociodemographic characteristics}

Participants' sociodemographic characteristics were collected from their medical records, including age, sex, civil status, education, former profession, NH length of stay, and number of visits per week by their SICs.

\section{Data collection}

After written informed consent to participation in the study was provided by the CIOAs or their legal representatives, the study nurse collected sociodemographic and health status data. Data on sociodemographic characteristics, symptoms and signs of delirium (CAM), delirium risk factors, cognition (MMSE and CDR), physical status (ADL), comorbidities (CIRS-G), and medication use were collected from patient records. Tools assessing the severity of the cognitive impairment (CDR), depression (Cornell), and physical autonomy (Katz) were completed in collaboration with the psychiatric unit's nursing team. CIOAs were assessed on their mental status and how they optimized their environmental and personal conditions.

\section{Assessment of the QoL}

The QoL-AD-fv questionnaire was assessed in face-to-face meetings with CIOAs and their SICs and separately with the PC. CIOAs with an MMSE score $>12(n=9)$ completed the QoL-AD-fv questionnaire in the presence of their SICs. When CIOAs ( $\mathrm{n}=9$ ) needed help filling in their questionnaire (MMSE<12), their SICs were involved. PCs completed each CIOA's questionnaire and transferred them to the study nurse. Completing the QoL-AD-fv instrument took about 15 minutes.

\section{Statistical analyses}

Categorical data were analyzed using descriptive statistics and exact tests (chi-squared and Fisher's exact tests). Continuous variables were examined by their distribution and summarized with the appropriate central tendency statistics, means, SD and/or median. Associations between sociodemographic variables and QoL-AD-fv and differences among CIOAs, SICs, the nurse, and the OT were analyzed using nonparametric statistics. Missing values were treated using the multiple imputation procedure. ${ }^{49}$ In the presentation of questionnaire responses, the scores of CIOAs who experienced significant problems answering the questions (and their SICs) are shown as a single, combined CIOA/SIC score. This was calculated by discussion between the CIOA/SIC and the study nurse. The statistical level of significance was set at by considering the number of variables and the range of the databases $(P \leq 0.05$, 95\% CI). Quantitative data were analyzed using IBM-SPSS ${ }^{\circledR}$ (version 22.0; IBM Corporation, Armonk, NY, USA).

\section{Qualitative study Sample}

The study population was composed of CIOAs living in the participating NH's psychiatric unit and their SICs, all of whom completed the baseline QoL-AD-fv. Recruitment took place between January and September 2016. CIOAs in end-of-life situations were excluded. SICs were eligible if they were regularly involved in caring for a CIOA. The nurse supervisor invited eligible CIOAs and their SICs to participate in study interviews, and the researchers had not met the participants before them. Fifteen CIOAs and nine SICs agreed to participate. Basic sociodemographic characteristics are presented in Table 1.

\section{Methods}

An interview guide with questions matched to the specific domains of the QoL-AD-fv was used to conduct the interviews using open-ended questions (eg, "What do you think influences your quality of life?"). The study nurse completed the interviews in a quiet room in the nursing unit The interviews were conducted 2-4 weeks after completing the QoL-AD-fv questionnaire. Data collection ceased when data saturation was attained. The interviews lasted between 15 and 30 minutes.

\section{Analysis}

Collected qualitative data were analyzed using a deductive content analysis method outlined by Elo and Kyngäs ${ }^{50,51}$ and Hsieh and Shannon. ${ }^{52}$ This analysis involved several steps: 1) the verbatim transcriptions of recorded interviews were read several times thoroughly to obtain a feeling for the study aims; 2) transcriptions were coded into meaning-units; 
Table I Sociodemographic data of the cognitively impaired older adults in a $\mathrm{NH}(\mathrm{n}=15)$

\begin{tabular}{|c|c|c|}
\hline Variables & $n=15$ & $\%$ \\
\hline $\begin{array}{l}\text { Sex } \\
\qquad \text { Male/female }\end{array}$ & $5 / 10$ & $33.3 / 66.7$ \\
\hline $\begin{array}{l}\text { Age (years) } \\
\text { Range } \\
\text { Mean (SD) } \\
\text { Median }\end{array}$ & $\begin{array}{l}77 / 94 \\
86.1(6.2) \\
88\end{array}$ & $\begin{array}{l}- \\
- \\
-\end{array}$ \\
\hline $\begin{array}{l}\text { Civil status } \\
\text { Married } \\
\text { Widowed } \\
\text { Single } \\
\text { Divorce/separated }\end{array}$ & $\begin{array}{l}5 \\
5 \\
2 \\
3\end{array}$ & $\begin{array}{l}33.3 \\
33.3 \\
13.3 \\
20.0\end{array}$ \\
\hline $\begin{array}{l}\text { Education } \\
\text { Not documented } \\
\text { Apprenticeship } \\
\text { Obligatory schooling } \\
\text { Vocational school } \\
\text { Federal secondary school } \\
\text { diploma }\end{array}$ & $\begin{array}{l}6 \\
2 \\
1 \\
5 \\
1\end{array}$ & $\begin{array}{l}40.0 \\
13.3 \\
6.7 \\
33.3 \\
6.7\end{array}$ \\
\hline $\begin{array}{l}\text { Profession } \\
\text { Independent artisanal job } \\
\text { Housewife } \\
\text { Paramedical staff } \\
\text { Engineer } \\
\text { Teacher } \\
\text { Industrial or hotel } \\
\text { employees }\end{array}$ & $\begin{array}{l}3 \\
3 \\
4 \\
2 \\
1 \\
2\end{array}$ & $\begin{array}{l}20.0 \\
20.0 \\
26.7 \\
13.3 \\
6.7 \\
13.7\end{array}$ \\
\hline $\begin{array}{l}\text { NH length of stay } \\
\text { Range } \\
\text { Mean (SD) } \\
\text { Median }\end{array}$ & $\begin{array}{l}2 \text { months } / 16.3 \text { years } \\
2.7 \text { years ( } 4.1 \text { years) } \\
\text { I. } 3 \text { years }\end{array}$ & $\begin{array}{l}- \\
- \\
-\end{array}$ \\
\hline $\begin{array}{l}\text { Number of visits per week } \\
0 \\
1 \\
2 \\
3\end{array}$ & $\begin{array}{l}9 \\
2 \\
1 \\
3\end{array}$ & $\begin{array}{l}60.0 \\
13.3 \\
6.7 \\
20.0\end{array}$ \\
\hline
\end{tabular}

Abbreviation: $\mathrm{NH}$, nursing home.

3) meaning-units were condensed with regards to preserve the meaning and labeling of those units as per the study aims; 4) condensed meaning-units were reviewed if new meaning-units fitted with the study aims; 5) meaning-units were sorted into subcategories and categories; and 6) significant themes were drawn out. Qualitative data were imported into and analyzed with NVivo software ${ }^{\circledR}$, version 11. (QSR International Pty, Doncaster, VIC, Australia).

\section{Mixed method integration}

Our mixed methods were integrated by connecting the quantitative survey and interview study through sampling, matching survey item domains to interview questions, merging quantitative and qualitative results into themes, and through discussion.

\section{Ethics approval}

The research was conducted in accordance with the Declaration of Helsinki and approved by the Human Research Ethics Committee of the Canton Vaud (no 427/15). Written informed consent was obtained from all participants before data collection, and confidentiality was ensured and preserved in all cases.

\section{Results \\ Participants}

The sample was composed of 16 CIOAs and nine SICs. Half of the eligible PCs agreed to participate: one nurse and one OT. Nine CIOAs were not eligible for inclusion in the study (six endof-life situations and three refusals by legal representatives). One CIOA participant died during the study (Figure 2).

\section{Sociodemographic characteristics and clinical and health data}

The average age of the CIOAs was 86 years. The majority were women $(66.7 \%)$, educated to a secondary level, with previous tertiary, service-oriented professional activities. The average length of stay in the institution was 2.7 years (range, 2 months to 16.3 years). Forty percent of the CIOAs had at least one visit per week from their SICs. These were mainly spouses or children, and one CIOA had no SICs. The PCs, one nurse and OT, had an average age of 35.5 years, had worked in the NH for more than 5 years (Table 1).

As expected, CIOAs showed symptoms and signs of severe physical and cognitive frailty. Physical frailty manifested itself as a need for aid in at least two or three ADLs and a high CIRS-G score. With some patients, this involved such incapacities as visual disabilities and deafness or balance disorders and increased risks of falling. Cognitive impairment was present among all the recruited CIOAs but took different forms: a CDR of severe dementia and a moderate to severe major cognitive disorder (MMSE) were combined in some CIOAs with the signs and symptoms of a subsyndromal delirium (CAM) and depression (Cornell Scale; Table 2).

\section{QoL}

Table 3 presents the mean scores (SD) for each of the 13 items on the QoL-AD-fv questionnaire for the CIOAs, SICs, the nurse, and PCs. Table 4 compares the total mean scores on the QoL-AD-fv questionnaire among the CIOAs, SICs, the nurse, and the OT. No significant differences were found between the CIOAs, SICs, the nurse, and the OT. However, we did find associations between participants' objective QoL and the number of visits per week from SICs as well as comorbidities (Table 5). 


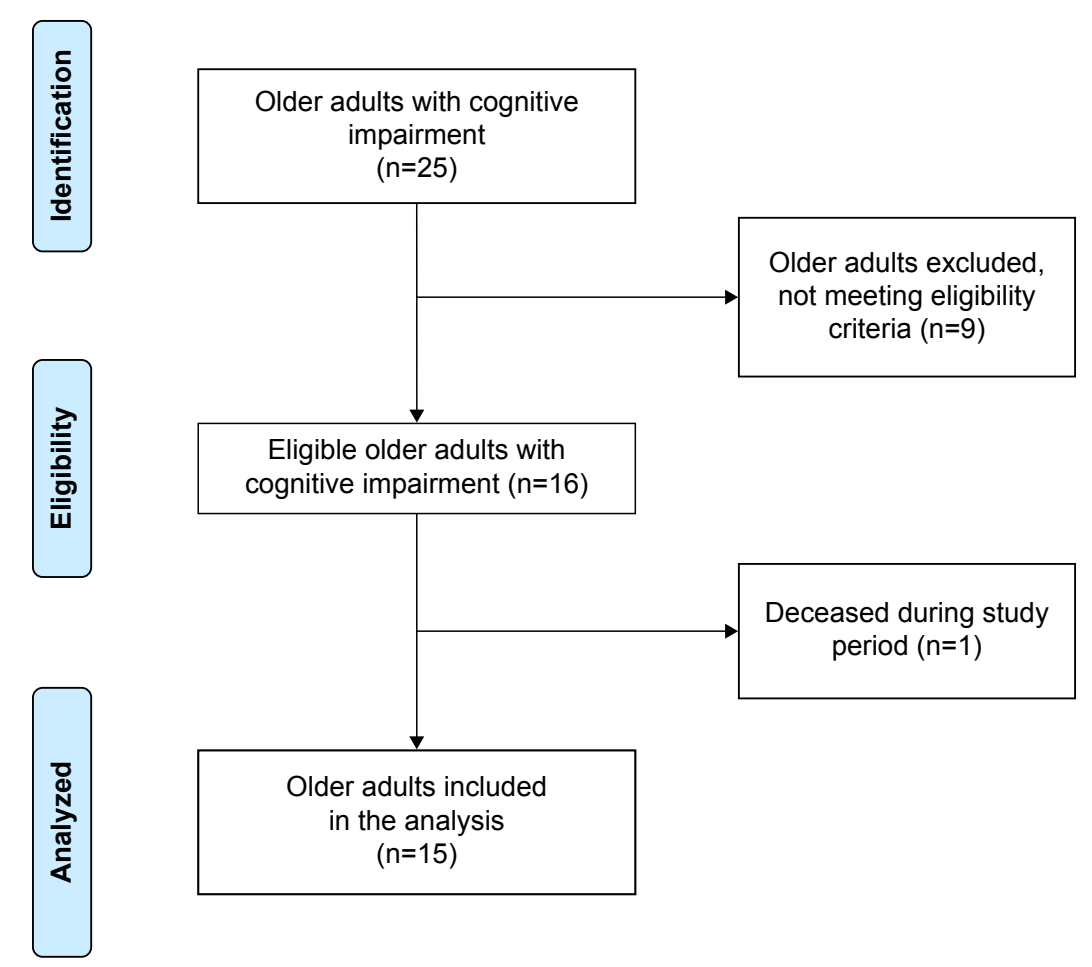

Figure 2 Flowchart representing the recruitment of older adults with cognitive impairment $(n=15)$.

\section{Perceptions of QoL}

Six individual interviews were conducted with CIOAs with an MMSE score of $>12$ points; the other nine interviews were done with the SICs in attendance. Twelve interviews were recorded, two CIOAs refused to be recorded, and one interview was done through telephone. Four themes stood out.

\section{Human dignity and acceptance}

This theme demonstrated the importance of social interactions between CIOAs and their family members and friends. The majority of the CIOAs described their remaining family relationships as important. Regular (weekly) visits by SICs and friends were considered as important to CIOAs daily lives, and they were even expected.

"Is family important? Of course" [CIOA 4]; "Visits by friends and family" [CIOA 5]; "My two children [...] For me, it's family" [CIOA 9]; "A visit from one's wife" [CIOA

11]; "With my husband? Yes, I wait for him" [CIOA 12].

CIOAs and SICs mentioned that social interaction with family members offered moments of satisfaction and contributed to QoL. In addition, the quality of social interactions and relationships with family and friends were essential for the CIOAs and crucial to avoid loneliness and mood disorders.

"The other patients, they have to or three [visitors] at once"

[CIOA 2]; "We talked all morning" [CIOA 4]; "She talks a lot with the other residents" [SIC 7]; "Being with people" [CIOA 2]; "They come to visit me; we enjoy being together and chatting" [CIOA 12].

Finally, carers who were kind, respectful, accepting, and good listeners were revealed as factors favoring good quality social interactions and relationships. However, SICs found that patients' limited social interactions with the nursing staff constituted a lack of care.

"She really loves to talk; she is very sociable" [SIC 7]; "She's lonely, $[\ldots]$ they should talk to her more to communicate"

[SIC 6]; "[she needs] to be more supported" [SIC 14].

\section{Development and existence}

CIOAs see activities or hobbies as recreational moments that allow them to feel real pleasure. They also keep them interested, either in a manual or an artistic activity. Both CIOAs and SICs mentioned the importance of maintaining interactions outside of the $\mathrm{NH}$ through activities such as walks or participating in other facets of community life. These elements support QoL and encourage CIOAs to care about their living environment.

\footnotetext{
"Activities [...] I enjoy going to them" [CIOA 2]; "manual activities ... building a table" [CIOA 5]; "having a hobby [...] finding something to read" [CIOA 5]; "music" [CIOA 13]; Is painting an activity you often do? "Often [...]" [CIOA 16].
} 
Table 2 Health and clinical status of the CIOAs $(n=15)$

\begin{tabular}{|l|l|}
\hline Health status & $\mathbf{n}=\mathbf{I 5}$ \\
\hline ADL (Katz index; 6=independent; 0=dependent) & \\
$\quad$ Range & $0-6$ \\
Mean (SD) & $2.7(2.1)$ \\
Median & 3.0 \\
\hline $\begin{array}{l}\text { Comorbidities (CIRS-G) } \\
\text { Range }\end{array}$ & \\
Mean (SD) & $5-24$ \\
Median & $14.7(4.7)$ \\
\hline Pain (Algoplus $\left.{ }^{\circledR}\right)$ & 15.0 \\
Pain & \\
No pain & $1(6.7 \%)$ \\
\hline CDR & $14(93.3 \%)$ \\
Range & \\
Prevalence & $3-3$ \\
\hline MMSE & $15(100 \%)$ \\
Range & \\
Mean (SD) & $0-19$ \\
Median & $9.5(7.7)$ \\
\hline MMSE of severe cases & 11.0 \\
Range & \\
Mean (SD) & $0-29$ \\
Median & $17.8(9.9)$ \\
\hline CAM & 23 \\
CAM positive & \\
CAM negative & 0 \\
CAM subsyndromal & 0 \\
\hline Cornell Scale for Depression in Dementia & 2 \\
Range & $1-18$ \\
Mean (SD) & $6.2(4.9)$ \\
Median (IQR-75) & $5.0(4.1)$ \\
\hline Abbriatons: ADL acis & \\
\hline
\end{tabular}

Abbreviations: ADL, activity of daily living; CAM, Confusion Assessment Method; CDR, clinical dementia rating; CIOA, cognitively impaired older adult; CIRS-G, Cumulative Illness Rating Scale for Geriatrics; MMSE, Mini-Mental State Examination.
"Being able to see nature and animals" [SIC 3]; "Strolls, being outside" [CIOA 5]; "She loves walks" [SIC 6]; "She really loves gardening" [SIC 7]; "I need to go out to see the garden and the sheep" [CIOA 11]; "Going for a car ride, the flowers" [SIC 14].

On the other hand, interaction with the outside world can also be a nuisance for the $\mathrm{NH}$ residents, especially exposure to noise.

"The traffic, the noise from the cars" [CIOA 12]; "The lawnmower" [CIOA 15].

\section{Functionality and health}

CIOAs mentioned that the importance of their health went far beyond their illness and its impacts. Maintaining physical and psychological health was something that CIOAs asked of their professional care team.

What makes you happy? Good health? "Little things" [CIOA 4]; Physical fitness? "Yes, that too, [...] you have to keep fit" [CIOA 5]; "I want to be better both physically and mentally" [CIOA 11].

SICs observed changes in illnesses and their impacts on CIOAs. SICs thought that the following factors influenced QoL.

"It's her illness that is changing her" [SIC 3]; "Her physical health has an impact on her quality of life" [SIC 3]; "She has trouble finding her words and she is losing her balance."

Table 3 Comparison of the mean scores (SD) for each of the 13 items on the QoL-AD-fv questionnaire for CIOAs, SICs, the nurse, and the occupational therapist

\begin{tabular}{|c|c|c|c|c|c|c|c|c|c|}
\hline & \multicolumn{2}{|l|}{ CIOAs } & \multicolumn{2}{|l|}{ SICs } & \multicolumn{2}{|l|}{ Nurse } & \multicolumn{2}{|c|}{ Occupational therapist } & \multirow[t]{2}{*}{$P$-value ${ }^{a}$} \\
\hline & Mean (SD) & $95 \% \mathrm{Cl}$ & Mean (SD) & $95 \% \mathrm{Cl}$ & Mean (SD) & $95 \% \mathrm{Cl}$ & Mean (SD) & $95 \% \mathrm{Cl}$ & \\
\hline Question I & $2.4(0.4)$ & $2.2-2.7$ & $2.4(0.9)$ & $1.9-2.9$ & $2.3(0.6)$ & $1.9-2.6$ & $2.0(0.7)$ & $1.6-2.4$ & 0.310 \\
\hline Question 2 & $2.2(0.5)$ & $1.9-2.5$ & $2.0(0.8)$ & $1.5-2.5$ & $2.2(1.0)$ & $1.6-2.8$ & $2.2(0.7)$ & $1.7-2.6$ & 0.151 \\
\hline Question 3 & $2.3(0.4)$ & $2.3-2.7$ & $2.4(0.7)$ & $2.0-2.8$ & $2.7(0.6)$ & $2.3-3.0$ & $2.0(0.7)$ & I.7-2.4 & 0.243 \\
\hline Question 4 & $2.4(0.4)$ & $2.2-2.7$ & $2.5(0.8)$ & $2.0-2.9$ & $3.5(0.5)$ & $3.2-3.8$ & $2.3(0.7)$ & I.8-2.7 & 0.148 \\
\hline Question 5 & $1.9(0.5)$ & I.7-2.2 & $1.9(0.6)$ & $1.6-2.3$ & $1.9(0.7)$ & $1.5-2.3$ & $2.8(0.8)$ & $2.4-3.2$ & 0.056 \\
\hline Question 6 & $3.2(0.5)$ & $2.9-3.5$ & $3.2(0.7)$ & $2.9-3.6$ & $3.4(0.9)$ & $3.0-3.9$ & $3.0(I . I)$ & $2.4-3.6$ & $0.54 I$ \\
\hline Question 7 & $3.4(0.4)$ & $3.1-3.6$ & $3.2(1.1)$ & $2.6-3.7$ & $3.5(0.8)$ & $3.1-4.0$ & $2.9(1.1)$ & $2.3-3.5$ & 0.174 \\
\hline Question 8 & 2.I (0.6) & I.8-2.5 & $2.4(1.0)$ & $1.9-3.0$ & $3.0(0.8)$ & $2.5-3.5$ & $2.3(0.7)$ & $1.9-2.7$ & 0.274 \\
\hline Question 9 & $2.5(0.7)$ & 2.I-2.8 & $2.1(1.0)$ & 1.5-2.6 & $3.0(0.4)$ & $2.8-3.2$ & $2.7(0.8)$ & $2.3-3.2$ & 0.105 \\
\hline Question 10 & $2.4(0.8)$ & $2.4-2.8$ & $2.0(I . I)$ & I.4-2.7 & $1.9(0.6)$ & $1.5-2.2$ & $2.4(0.8)$ & $1.9-2.8$ & $0.4 I I$ \\
\hline Question II & $2.1(0.6)$ & 1.8-2.5 & $1.7(0.9)$ & 1.2-2.2 & $2.2(0.7)$ & $1.8-2.6$ & $2.7(0.7)$ & $2.3-3.1$ & 0.214 \\
\hline Question 12 & $2.7(0.7)$ & $2.3-3.1$ & $2.9(0.9)$ & $2.4-3.4$ & I.4 (0.6) & $1.1-1.8$ & $2.6(0.6)$ & $2.2-2.9$ & 0.234 \\
\hline Question I3 & $2.6(0.6)$ & $2.2-2.9$ & $2.3(0.7)$ & $1.9-2.6$ & $2.0(0.8)$ & $1.6-2.4$ & $2.6(0.9)$ & $2.1-3.1$ & 0.363 \\
\hline Total & 32.4 (3.I) & $30.7-34.2$ & 30.9 (6.5) & $27.3-34.5$ & $32.4(5.0)$ & $30.0-35.2$ & $32.4(7.0)$ & $28.6-36.3$ & 0.450 \\
\hline
\end{tabular}

Notes: aKruskal-Wallis test; significant $P \leq 0.05 ; 95 \% \mathrm{Cl}$.

Abbreviations: CIOA, cognitively impaired older adult; QoL-AD-fv, quality of life-Alzheimer's disease - French version; SIC, significant informal caregiver. 
Table 4 Comparison between the total mean scores on the QoL-AD-fv questionnaire for CIOAs $(n=15)$, SICs $(n=9)$, the nurse $(n=I)$, and the occupational therapist $(n=I)$

\begin{tabular}{|l|l|l|}
\hline & Mean scores (SD) & P-value $^{\mathrm{a}}$ \\
\hline Participants (CIOAs) & $32.4(3.1)$ & - \\
\hline Informal caregiver (SICs) & $32.4(7.0)$ & $0.07 I$ \\
\hline Nurse & $32.4(5.0)$ & 0.777 \\
\hline Occupational therapist & $30.9(6.5)$ & 0.589 \\
\hline
\end{tabular}

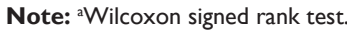

Abbreviations: CIOA, cognitively impaired older adult; QoL-AD-fv, quality of Life-Alzheimer's Disease - French version; SIC, significant informal caregiver.

She used to be an active person [...] since she has been ill, she has been transformed" [SIC 7].

Our findings show that SICs and CIOAs have different perceptions about concepts concerning health and illness. Maintaining good health and certain residual skills are paramount to CIOAs. On the other hand, SICs focused more on the changes or losses occurring as their loved one's illness progressed.

\section{Recognition and safety}

Certain patients' words highlighted that respect for their private lives and physical privacy were important factors for both CIOAs and their SICs. Despite the presence of major neurocognitive disorders, with a decrease in executive capacity, CIOAs still expressed their needs for that respect, which is an intrapersonal factor linking patients to their life history and personality.

"Her private life is important, it's secret" [SIC 8]; "People who get involved in all sorts of things that aren't their

Table 5 Associations among components of health status, sociodemographic characteristics, and ClOAs' perceptions of QoL (QoL-AD-fv) (n=15)

\begin{tabular}{|l|l|l|}
\hline Health statuses of CIOAs & QoL-AD-fv of CIOAs & $\boldsymbol{P}_{\text {-value }}$ \\
\hline ADL (Katz) & 0.007 & 0.878 \\
\hline MMSE & -0.372 & 0.223 \\
\hline Cornell Depression Scale & -0.176 & 0.517 \\
\hline Pain assessment (Algoplus ${ }^{\circledR}$ ) & -0.433 & 0.105 \\
\hline Comorbidities (CIRS-G) & -0.540 & $0.046^{\mathrm{b}}$ \\
\hline $\begin{array}{l}\text { Sociodemographic } \\
\text { characteristics }\end{array}$ & QoL-AD-fv of CIOAs & P-value $^{\mathrm{a}}$ \\
\hline Age & 0.535 & 0.066 \\
\hline Length of stay & 0.136 & 0.728 \\
\hline Number of SIC visits/week & -0.563 & $0.036^{\mathrm{b}}$ \\
\hline
\end{tabular}

Notes: aKendall's tau-B. 'Significant $P$-value $<0.05$.

Abbreviations: $A D L$, activity of daily living; $C I O A$, cognitively impaired older adult; CIRS-G, Cumulative IIIness Rating Scale for Geriatrics; MMSE, Mini-Mental State Examination; QoL, quality of life; QoL-AD-fv, quality of life-Alzheimer's disease French version; SIC, significant informal caregiver. business" [CIOA 9]; What upsets her? "Physical contact from other people, from strangers" [SIC 6]; "Each to their own business [...] I won't talk about it" [CIOA 4].

SICs see the context of care as an essential QoL factor for their CIOAs, and the elements which they believe are influential on that QoL are personalized care, minimal use of psychotropic drugs, a single room, clean, appropriate premises, and access to the NH garden, whether accompanied or alone.

\section{Discussion}

The present study revealed that CIOAs, SICs, and PCs all had different perceptions of CIOAs' QoL although those differences were not statistically significant. Comorbidities probably causing incapacitating discomfort - had a negative influence on CIOAs' QoL. Finally, visits from SICs did have a beneficial effect on CIOAs' perceptions of their QoL, but no statistically significant difference could be found between the QoL-AD-fv scores of patients who received at least one visit per week and those who did not get a weekly visit. These findings corroborate those of other studies carried out in psychogeriatric institutions in France and USA. ${ }^{53,54}$

Our interviews revealed the presence of a relationship between the components of CIOAs' health statuses (objective QoL) and their perceptions of their QoLs (subjective QoL). As expressed by the CIOAs, maintaining relationships with their families was an essential need, even at advanced stages of neurodegenerative illness. This need is expressed powerfully when OAs are placed in a psychiatric unit of an $\mathrm{NH}$, and this confirms the findings by Terada et al. ${ }^{14}$

Studies on the QoL in long-term care institutions underline the importance of maintaining and encouraging that social link. ${ }^{55}$ More specifically, studies among OAs with degenerative neurocognitive disorders and living in NHs report that these social and relational links are crucial. Although there have not been many studies on this subject, some have documented that these links help to reduce anxiety and support patients' well-being, especially during transitions of care, either following a hospitalization or directly from home. ${ }^{56,57}$ The authors note that QoL is especially important for maintaining the OA's position within their family's structure and for giving them happiness and support. ${ }^{58,59}$ Nevertheless, this approach must be completed by integrating the family into the NH resident's overall care, as an essential and integral member of the care team..$^{56,60}$

Our findings also showed that CIOAs expressed a need for activities that would help them to maintain their cognitive, physical, and psychological functions. Several scientific 
works have highlighted that much thought should go into the free-time activities offered to OAs in care institutions. ${ }^{8,19}$ Indeed, the activities on offer should reflect residents' needs and not simply be something to keep them busy. Particularly with residents suffering from degenerative neurocognitive disorders, however, activities should be aimed at the person's needs and adapted to their residual cognitive capacities. ${ }^{56,61}$ Similarly, putting in place appropriate activities and contributing to the overall QoL in an $\mathrm{NH}$ is a complex process, one requiring structure and several stages of planning. First, the precise assignment must be understood, and resources and residents needs must be evaluated. Programming and carrying out activities will have to be interdisciplinary, and how activities are evaluated will have to be discussed. ${ }^{62}$ Putting in place certain individual activities may also be important, especially if a resident has a disability preventing participation in group activities: this will limit the resident's feelings of boredom or isolation and will improve their QoL. Alternating between individual and group activities is to be preferred, especially if adapted to the resident's personality. ${ }^{58,62}$ There are criteria that enable activities to be adapted, so that they encourage and stimulate NH residents, rather than just keeping them occupied. ${ }^{56,63}$

Our findings showed that SICs and CIOAs had different perceptions of certain notions of health and illness. Maintaining health and residual skills were cited as essential by CIOAs. SICs, on the other hand, placed the emphasis on changes and physical and mental deteriorations linked to the progression of the OAs illness. These differences in perceptions are also found in other studies examining $\mathrm{NH}$ residents, their families, and nursing teams. ${ }^{57,64}$ It is noteworthy that these studies also found a differentiated view of health and illness.

The presence of major cognitive problems and diminished executive capacities mean that CIOAs are highly dependent. Nevertheless, just as they are able to recount their life stories or describe their personalities, COIAs can express how important their private lives and their personal privacy are. Other studies also raised the issues of respect for patients' private lives and the importance of having their personal belongings kept safe..$^{57,59}$ The nonrespect of these wishes can cause anxiety, weigh heavily on a CIOA's mind, and even manifest itself as disruptive behavior (part of the BPSD).$^{56}$ If caregivers can take these issues into consideration, they can significantly improve residents' daily lives, prevent anxiety linked to the loss of personal belongings or their own physical capacities, and thus avoid the BPSD.
Studies have shown how important the context of care is to patients' families. The literature underlines that the resources allotted to psychogeriatric units should be adapted to residents' levels of dependence, thus best ensuring the management of the different manifestations of their neurodegenerative illnesses. ${ }^{65,66}$ In this regard, studies have shown that it is important that care teams have been trained to recognize and manage the BPSD. ${ }^{28,67,68}$

In specialist psychogeriatric institutions, managing the BPSD and supporting patients in their day-to-day activities (basic self-care) put the appropriate conditions in place to promote QoL among OAs suffering from degenerative major neurocognitive disorders. ${ }^{69,70}$ Certain authors state that for OAs presenting with neurocognitive disorders and difficulties communicating, institutionalization would facilitate the redevelopment of communication through other residents, SICs, and PCs. ${ }^{70}$ However, OAs with dementia are particularly sensitive to their psychosocial environments; many of the BPSD can be put down to residents' new environments not being adequately adapted to the needs of persons suffering from this psychiatric syndrome of old age. ${ }^{71-73}$ OAs require support through professional, specialized, and intensive accompaniment and management because an advancing neurodegenerative illness and fewer human relationships can lead to withdrawal, introversion, and a progression to a complete cessation of communication and a higher prevalence of the BPSD. ${ }^{74}$

\section{Strengths and limitations}

We have identified some methodological and statistical limitations in the present study. First, the study was done in a single $\mathrm{NH}$, and the limited number of participating CIOAs and PCs means that any generalization of our results should be done with caution and not be transferred to other psychogeriatric care units.

Although the QoL-AD-fv questionnaire has been validated among a population living with neurocognitive disorders, it does have certain limitations when it comes to measuring QoL in patients with an MMSE score of $<10$ : using the QoL-AD-fv was difficult in some situations.

We revealed several types of problems during our study: the significant number of residents in end-of-life situations, the arrival of new residents, and the difficulties in getting some PCs and SICs to participate. When administering the QoL-AD-fv questionnaire, some SICs and one PC had difficulty understanding and answering questions. With two CIOAs, evaluation using the MMSE had to be stopped and rescheduled due to manifestations of BPSD. 
Nevertheless, the project's design and scientific rigor did allow us to draw some new insights on the subject, such as the importance of focusing on QoL among OAs suffering from severe dementia.

However, the chance to explore the QoL of NH residents with major neurocognitive disorders enabled us to reveal their specific needs, and, to date, few studies have looked at QoL in this population.

\section{Conclusion}

QoL has become a priority issue in long-term care institutions for OAs. The present study highlighted the feasibility of evaluating the QoL of CIOAs from objective, subjective, and functional viewpoints. Findings showed differences in perspectives among the carers who surround and support CIOAs. The strength of this study was the consensus obtained among the participants that QoL should be a primary outcome for daily care of CIOAs.

\section{Acknowledgments}

The authors wish to thank all the participants, significant informal caregivers, and professional caregivers for their participation in this study. We especially wish to acknowledge the Eben-Hézer Foundation for its generous grant for the conduct of this research project. This study was funded by the Eben-Hézer Foundation, Lausanne, Switzerland. The funders played no role in the design and conduct of the study, data collection, management, analysis, or interpretation of the data, nor in the preparation, review, or approval of the final manuscript.

\section{Author contributions}

All the authors contributed to the development of this study concept, the study design, and drafting the manuscript. They all approved the final version and agreed to be held accountable for all aspects of the work.

\section{Disclosure}

The authors report no conflicts of interest in this work.

\section{References}

1. OECD: Health status includes the length of people's lives, as well as their physical and mental health which may be affected by infectious diseases, chronic diseases and injuries. Available from: https://www. oecd-ilibrary.org/social-issues-migration-health/health-status/indicatorgroup/english_bd12d298-en. Accessed October 11, 2018.

2. OFS. Encyclopédie statistique de la Suisse. Secondary Encyclopédie statistique de la Suisse; 2012.
3. Abrahamson K, Clark D, Perkins A, Arling G. Does cognitive impairment influence quality of life among nursing home residents? Gerontologist. 2012;52(5):632-640.

4. Chang E, Daly J, Johnson A, et al. Challenges for professional care of advanced dementia. Int J Nurs Pract. 2009;15(1):41-47.

5. Curaviva. Conception de la qualité de vie pour des personnes âgées ayant besoin de soutien. Available from: https://www.curaviva.ch/ Infos-specialisees/Demence/Fondements-ethiques-et-juridiques/ PAmcM/?id=B3E8E241-2B10-4907-90B8B666FEF0E128\&method= article.detail\&keyword=qualit $\%$ C3\%A9\%20de $\% 20$ vie. Accessed October 11, 2018.

6. Cordner Z, Blass DM, Rabins PV, Black BS. Quality of life in nursing home residents with advanced dementia. J Am Geriatr Soc. 2010; 58(12):2394-2400.

7. Brémault-Phillips S, Germani T, Sacrey L-AR, Friesen S, Lee J. Managing disruptive behaviours exhibited by older adults with mental health, addictions and neurocognitive conditions in Alberta: a mixed methods approach. Geriatric Mental Health Care. 2015;3(2):21-27.

8. Willemse BM, Smit D, de Lange J, Pot AM. Nursing home care for people with dementia and residents' quality of life, quality of care and staff well-being: design of the Living Arrangements for people with Dementia (LAD)-study. BMC Geriatr. 2011;11:11.

9. Beerens HC, Zwakhalen SM, Verbeek H, Ruwaard D, Hamers JP. Factors associated with quality of life of people with dementia in longterm care facilities: a systematic review. Int J Nurs Stud. 2013;50(9): 1259-1270.

10. Alzheimer's Association. 2013 Alzheimer's Disease Facts and Figures. Alzheimers Dement. 2013;9(2):208-245.

11. Chouiter L, Wodchis WP, Abderhalden C, von Gunten A. Resident health-related quality of life in Swiss nursing homes. Eur Psychiatry. 2015;30(5):549-554.

12. Billington J, Carroll J, Davis P, Healey C, Kinderman P. A literaturebased intervention for older people living with dementia. Perspect Public Health. 2013;133(3):165-173.

13. Tilly J, Reed P. Interventions that optimize quality dementia care: a comprehensive literature search selects the best evidence-based interventions to improve quality dementia care in LTC facilities. Can Nurs Home. 2005;16(3):13-21.

14. Terada S, Oshima E, Yokota O, et al. Person-centered care and quality of life of patients with dementia in long-term care facilities. Psychiatry Res. 2013;205(1-2):103-108.

15. Sousa MF, Santos RL, Arcoverde C, et al. Quality of life in dementia: the role of non-cognitive factors in the ratings of people with dementia and family caregivers. Int Psychogeriatr. 2013;25(7):1097-1105.

16. Moyle W, O’Dwyer S. Quality of life in people living with dementia in nursing homes. Curr Opin Psychiatry. 2012;25(6):480-484.

17. Ebrahim S. Clinical and public health perspectives and applications of health-related quality of life measurement. Soc Sci Med. 1995;41(10): 1383-1394.

18. Group TW. The World Health Organization Quality of Life assessment (WHOQOL): position paper from the World Health Organization. Soc Sci Med. 1995;41(10):1403-1409.

19. Wetzels RB, Zuidema SU, de Jonghe JF, Verhey FR, Koopmans RT. Determinants of quality of life in nursing home residents with dementia. Dement Geriatr Cogn Disord. 2010;29(3):189-197.

20. Martin M, Schneider R, Eicher S, Moor C. The Functional Quality of Life (fQOL)-Model. GeroPsych. 2012;25(1):33-40.

21. Jonker C, Gerritsen DL, Bosboom PR, van der Steen JT. A model for quality of life measures in patients with dementia: Lawton's next step. Dement Geriatr Cogn Disord. 2004;18(2):159-164.

22. Rabins PV, Black BS. Measuring quality of life in dementia: purposes, goals, challenges and progress. Int Psychogeriatr. 2007;19(3): 401-407.

23. Byrne-Davis LM, Bennett PD, Wilcock GK. How are quality of life ratings made? Toward a model of quality of life in people with dementia. Qual Life Res. 2006;15(5):855-865. 
24. Bowling A. What things are important in people's lives? A survey of the public's judgements to inform scales of health related quality of life. Soc Sci Med. 1995;41(10):1447-1462.

25. Logsdon RG, Gibbons LE, Mccurry SM, Teri L. Quality of life in Alzheimer's disease: Patient and caregiver reports. JMent Health Aging. 1999;5(1):21-32.

26. Wolak A, Novella JL, Drame M, et al. Transcultural adaptation and psychometric validation of a French-language version of the QoL-AD. Aging Ment Health. 2009;13(4):593-600.

27. Logsdon RG, Gibbons LE, Mccurry SM, Teri L. Quality of life in Alzheimer's disease: patient and caregiver reports. Journal of Mental Health and Aging. 1999;5:21-32.

28. Ballard C, O'Brien J, James I, et al. Quality of life for people with dementia living in residential and nursing home care: the impact of performance on activities of daily living, behavioral and psychological symptoms, language skills, and psychotropic drugs. Int Psychogeriatr. 2001;13(1):93-106.

29. Barca ML, Engedal K, Laks J, Selbæk G. Quality of life among elderly patients with dementia in institutions. Dement Geriatr Cogn Disord. 2011;31(6):435-442.

30. Weiner MF, Martin-Cook K, Svetlik DA, Saine K, Foster B, Fontaine CS. The quality of life in late-stage dementia (QUALID) scale. J Am Med Dir Assoc. 2000;1(3):114-116.

31. Moyle W, Fetherstonhaugh D, Greben M, Beattie E, Lg A, AusQoL Group. Influencers on quality of life as reported by people living with dementia in long-term care: a descriptive exploratory approach. BMC Geriatr. 2015; 15:50.

32. Droes RM, Boelens-van der Knoop ECC, Bos J. Quality of life in dementia in perspective: an explorative study of variations in opinions among people with dementia and their professional caregivers, and in literature. Dementia. 2006;5(4):533-558.

33. Katz S, Akpom CA. 12. Index of ADL. Med Care. 1976;14(5 Suppl): 116-118.

34. Luttenberger K, Schmiedeberg A, Gräßel E. Activities of daily living in dementia: revalidation of the E-ADL test and suggestions for further development. BMC Psychiatry. 2012;12:208.

35. Katz S, Ford AB, Moskowitz RW, Jackson BA, Jaffe MW. Studies of illness in the aged. the index of adl: a standardized measure of biological and psychosocial function. JAMA. 1963;185:914-919.

36. Gompertz P, Pound P, Ebrahim S. Validity of the extended activities of daily living scale. Clin Rehabil. 1994;8(4):275-280.

37. Folstein MF, Folstein SE, Mchugh PR. "Mini-mental state". A practical method for grading the cognitive state of patients for the clinician. J Psychiatr Res. 1975;12(3):189-198.

38. Naugle RI, Kawczak K. Limitations of the Mini-Mental State Examination. Cleve Clin J Med. 1989;56(3):277-281.

39. Derouesné C, Poitreneau J, Hugonot L, Kalafat M, Dubois B, Laurent B. Le mini-mental state examination (MMSE): un outil pratique pour l'évaluation de l'état cognitif des patients par le clinicien, version française consensuelle. La Presse Médicale. 1999;28(21): 1141-1148.

40. Morris JC. The Clinical Dementia Rating (CDR): current version and scoring rules. Neurology. 1993;43(11):2412-2414.

41. O'Bryant SE, Waring SC, Cullum CM, et al. Staging dementia using Clinical Dementia Rating Scale Sum of Boxes scores: a Texas Alzheimer's research consortium study. Arch Neurol. 2008;65(8): 1091-1095.

42. Laplante J, Cole M, Mccusker J, Singh S, Ouimet MA. Confusion Assessment Method. Validation of a French-language version. Perspect Infirm. 2005;3(1):12-20.

43. Wei LA, Fearing MA, Sternberg EJ, Inouye SK. The Confusion Assessment Method: a systematic review of current usage. J Am Geriatr Soc. 2008;56(5):823-830.

44. Hair JKJ, Black WC, Babin BJ, Anderson RE. Multivariate Data Analysis: A Global Perspective. 7th edn. New Jersey, USA: Pearson Education Inc; 2010.
45. Huntley AL, Johnson R, Purdy S, Valderas JM, Salisbury C. Measures of multimorbidity and morbidity burden for use in primary care and community settings: a systematic review and guide. Ann Fam Med. 2012; 10(2):134-141.

46. Miller MD, Paradis CF, Houck PR, et al. Rating chronic medical illness burden in geropsychiatric practice and research: application of the Cumulative Illness Rating Scale. Psychiatry Res. 1992;41(3):237-248.

47. Linn BS, Linn MW, Gurel L. Cumulative illness rating scale. J Am Geriatr Soc. 1968;16(5):622-626.

48. Alexopoulos GS, Abrams RC, Young RC, Shamoian CA. Cornell Scale for Depression in Dementia. Biol Psychiatry. 1988;23(3):271-284.

49. Sterne JA, White IR, Carlin JB, et al. Multiple imputation for missing data in epidemiological and clinical research: potential and pitfalls. BMJ. 2009;338:b2393.

50. Burla L, Knierim B, Barth J, Liewald K, Duetz M, Abel T. From text to codings: intercoder reliability assessment in qualitative content analysis. Nurs Res. 2008;57(2):113-117.

51. Elo S, Kyngäs $H$. The qualitative content analysis process. J Adv Nurs. 2008;62(1):107-115.

52. Hsieh HF, Shannon SE. Three approaches to qualitative content analysis. Qual Health Res. 2005;15(9):1277-1288.

53. Chouiter L, Wodchis WP, Abderhalden C, von Gunten A. Resident health-related quality of life in Swiss nursing homes. Eur Psychiatry. 2015;30(5):549-554.

54. Crespo M, Bernaldo de Quirós M, Gómez MM, Hornillos C. Quality of life of nursing home residents with dementia: a comparison of perspectives of residents, family, and staff. Gerontologist. 2012;52(1): 56-65.

55. Xu D, Kane RL, Shamliyan TA. Effect of nursing home characteristics on residents' quality of life: a systematic review. Arch Gerontol Geriatr. 2013;57(2):127-142.

56. Milte R, Shulver W, Killington M, Bradley C, Ratcliffe J, Crotty M. Quality in residential care from the perspective of people living with dementia: the importance of personhood. Arch Gerontol Geriatr. 2016; 63:9-17.

57. Pihet S, Etter S, Lemarechal F, Maggiori C. Qualité de vie en établissements médico-sociaux selon les cadres et les résidents. Revue Francophone Internationale De Recherche Infirmière. 2016;2(3): 147-158.

58. Moyle W, Fetherstonhaugh D, Greben M, Beattie E. Influencers on quality of life as reported by people living with dementia in longterm care: a descriptive exploratory approach. BMC Geriatr. 2015; 15:50.

59. Dröes R-M, Boelens-van der Knoop ECC, Bos J. Quality of life in dementia in perspective: an explorative study of variations in opinions among people with dementia and their professional caregivers, and in literature. Dementia. 2006;5(4):533-558.

60. Talbolt LR, Landry M. L'intégration des proches aidants dans les milieux cliniques. In: Voyer $\mathrm{P}$, editor. Soins infirmiers aux aînés en perte d'autonomie. 2nd ed. Saint-Laurent, Québec: Éditions du Renouveau pédagogique; 2013:565-576.

61. Beerens HC, Zwakhalen SM, Verbeek H, et al. The relation between mood, activity, and interaction in long-term dementia care. Aging Ment Health. 2018;22(1):26-32.

62. Trudel J. Le Loisir. In: Voyer P, editor. Soins infirmiers aux â̂nés en perte d'autonomie. 2nd edn. Saint-Laurent, Québec: Éditions du Renouveau pédagogique; 2013:577-586.

63. Mermoud BV, Morin D. Regards croisés entre l'évaluation de la qualité de vie perçue par le résident hébergé en établissement médico-social et par le soignant référent. Rech Soins Infirm. 2016;3;126:38-50.

64. Xie B, Watkins I, Golbeck J, Huang M. Understanding and Changing Older Adults' Perceptions and Learning of Social Media. Educ Gerontol. 2012;38(4):282-296.

65. Yaffe MJ, Orzeck P, Barylak L. Family physicians' perspectives on care of dementia patients and family caregivers. Can Fam Physician. 2008;54(7):1008-1015. 
66. Crespo M, Hornillos C, Gómez MM. Dementia special care units: a comparison with standard units regarding residents' profile and care features. Int Psychogeriatr. 2013;25(12):2023-2031.

67. Rokstad AM, Røsvik J, Kirkevold Ø, Selbaek G, Saltyte Benth J, Engedal K. The effect of person-centred dementia care to prevent agitation and other neuropsychiatric symptoms and enhance quality of life in nursing home patients: a 10-month randomized controlled trial. Dement Geriatr Cogn Disord. 2013;36(5-6):340-353.

68. Fleiner T, Leucht S, Förstl H, Zijlstra W, Haussermann P. Effects of Short-Term Exercise Interventions on Behavioral and Psychological Symptoms in Patients with Dementia: A Systematic Review. J Alzheimers Dis. 2017;55(4):1583-1594.

69. Leon J, Ory MG. Effectiveness of Special Care Unit (SCU) placements in reducing physically aggressive behaviors in recently admitted dementia nursing home residents. Am J Alzheimers Dis. 1999;14(5): $270-277$.
70. Lai CK, Yeung JH, Mok V, Chi I. Special care units for dementia individuals with behavioural problems. Cochrane Database Syst Rev. 2009;(4):CD006470.

71. Lai CKY, Leung DDM, Kwong EWY, Lee RLP. Factors associated with the quality of life of nursing home residents in Hong Kong. International Nursing Review. 2015:62;120-129.

72. Hayen D, Gafford J. The ideal nursing home for dementia care. Alzheimers Care Today. 2008;9(2):162-163.

73. de Rooij AH, Luijkx KG, Schaafsma J, Declercq AG, Emmerink PM, Schols JM. Quality of life of residents with dementia in traditional versus small-scale long-term care settings: a quasi-experimental study. Int J Nurs Stud. 2012;49(8):931-940.

74. Gruneir A, Lapane KL, Miller SC, Mor V. Is dementia special care really special? A new look at an old question. J Am Geriatr Soc. 2008; 56(2):199-205.

\section{Clinical Interventions in Aging}

\section{Publish your work in this journal}

Clinical Interventions in Aging is an international, peer-reviewed journal focusing on evidence-based reports on the value or lack thereof of treatments intended to prevent or delay the onset of maladaptive correlates of aging in human beings. This journal is indexed on PubMed Central, MedLine,

\section{Dovepress}

CAS, Scopus and the Elsevier Bibliographic databases. The manuscript management system is completely online and includes a very quick and fair peer-review system, which is all easy to use. Visit http://www.dovepress. com/testimonials.php to read real quotes from published authors. 